\title{
The Importance of Failure: How Doing Impact Surveys That Fail Saves Trachoma Programs Money
}

Anthony W. Solomon, ${ }^{1 \star}$ Pamela J. Hooper, ${ }^{2}$ Mathieu Bangert, ${ }^{1}$ Upendo J. Mwingira, ${ }^{3}$ Ana Bakhtiari, ${ }^{2}$ Molly A. Brady, ${ }^{4}$ Christopher Fitzpatrick, ${ }^{1}$ lain Jones, ${ }^{5}$ George Kabona, ${ }^{3}$ Amir B. Kello, ${ }^{6}$ Tom Millar, ${ }^{5}$ Aryc W. Mosher, ${ }^{7}$ Jeremiah M. Ngondi, ${ }^{4}$ Andreas Nshala, ${ }^{8,9}$ Kristen Renneker, ${ }^{2}$ Lisa A. Rotondo, ${ }^{4}$ Rachel Stelmach, ${ }^{4}$ Emma M. Harding-Esch, ${ }^{10}$ and Mwelecele N. Malecela ${ }^{1}$

${ }^{1}$ Department of Control of Neglected Tropical Diseases, World Health Organization, Geneva, Switzerland; ${ }^{2}$ Task Force for Global Health, International Trachoma Initiative, Atlanta, Georgia; ${ }^{3}$ Neglected Tropical Disease Control Program, Ministry of Health, Community Development, Gender, Elderly and Children, Dodoma, United Republic of Tanzania; ${ }^{4}$ RTI International, Washington, District of Columbia; ${ }^{5}$ Sightsavers, Haywards Heath, United Kingdom; ${ }^{6}$ Expanded Special Project for Elimination of Neglected Tropical Diseases, World Health Organization Regional Office for Africa, Brazzaville, Congo; ${ }^{7}$ United States Agency for International Development, Washington, District of Columbia; ${ }^{8}$ IMA World Health, Dar es Salaam, United Republic of Tanzania; ${ }^{9}$ Department of International Maternal and Child Health, Faculty of Medicine and Pharmacy, University of

Uppsala, Uppsala, Sweden; ${ }^{10}$ Clinical Research Department, London School of Hygiene \& Tropical Medicine, London, United Kingdom

Abstract. Trachoma programs use annual antibiotic mass drug administration (MDA) in evaluation units (EUs) that generally encompass 100,000-250,000 people. After one, three, or five MDA rounds, programs undertake impact surveys. Where impact survey prevalence of trachomatous inflammation-follicular (TF) in 1 - to 9 -year-olds is $\geq 5 \%, \geq 1$ additional MDA rounds are recommended before resurvey. Impact survey costs, and the proportion of impact surveys returning TF prevalence $\geq 5 \%$ (the failure rate or, less pejoratively, the MDA continuation rate), therefore influence the cost of eliminating trachoma. We modeled, for illustrative EU sizes, the financial cost of undertaking MDA with and without conducting impact surveys. As an example, we retrospectively assessed how conducting impact surveys affected costs in the United Republic of Tanzania for 2017-2018. For EUs containing 100,000 people, the median (interquartile range) cost of continuing MDA without doing impact surveys is USD 28,957 $(17,581-36,197)$ per EU per year, whereas continuing MDA solely where indicated by impact survey results costs USD 17,564 (12,158-21,694). If the mean EU population is 100,000 , then continuing MDA without impact surveys becomes advantageous in financial cost terms only when the continuation rate exceeds $71 \%$. For the United Republic of Tanzania in 2017-2018, doing impact surveys saved enough money to provide MDA for $>1,000,000$ people. Although trachoma impact surveys have a nontrivial cost, they generally save money, providing EUs have $>50,000$ inhabitants, the continuation rate is not excessive, and they generate reliable data. If all EUs pass their impact surveys, then we have waited too long to do them.

\section{INTRODUCTION}

Trachoma causes blindness among the poorest people on the planet. ${ }^{1}$ Trachomatous blindness arises from repeated conjunctival Chlamydia trachomatis infection and the eyelid scarring that accumulates from the associated episodes of active (inflammatory) trachoma. ${ }^{2}$ The disease can be eliminated as a public health problem through a four-pronged strategy summarized by the acronym SAFE: surgery (S) for individuals with advanced, blinding disease; antibiotics (A) to clear C. trachomatis infection; and facial cleanliness $(F)$ and environmental improvement $(\mathrm{E})$ to reduce ocular $C$. trachomatis transmission.

The A, F, and E components of SAFE are delivered at the evaluation unit (EU) level. Evaluation units are generally populations of 100,000-250,000 people ${ }^{3}$; however, for practical reasons (including expediency at program inception ${ }^{3}$ or the size of local administrative divisions for healthcare management purposes ${ }^{4}$ ), they are sometimes smaller ${ }^{4}$ or larger $^{4,5}$ than this. Five annual rounds of EU-wide mass drug administration (MDA) of antibiotics active against ocular $C$. trachomatis ${ }^{6}$ are undertaken wherever the prevalence of the active trachoma sign trachomatous inflammation-follicular $\left(\mathrm{TF}^{7}\right)$ in 1- to 9-yearolds is $\geq 30 \%$. Three annual rounds are undertaken wherever the TF prevalence is $10-29.9 \%$. Where the TF prevalence is $5.0-9.9 \%$, the $\mathrm{WHO}$ recommends targeted treatment ${ }^{3}$; in

*Address correspondence to Anthony W. Solomon, Department of Control of Neglected Tropical Diseases, World Health Organization, Ave. Appia 20, Geneva 1211, Switzerland. E-mail: solomona@who.int recent years, this has been programmatically applied by targeting all EU residents in a single round of $\mathrm{MDA}^{8}$; the alternative targeting approaches of offering antibiotics only to individuals, ${ }^{9}$ households, ${ }^{10-12}$ or communities ${ }^{13}$ with active trachoma having been assessed as likely ineffective, impractical at scale, or both. Antibiotic MDA for trachoma should always be accompanied by implementation of $\mathrm{F}$ and $\mathrm{E}$; however, the evidence base for $F$ and $E$ is weaker than that for $A .{ }^{14,15}$

Because decisions concerning implementation of SAFE's $A$ component rest on EU-level prevalence of TF, reliable TF prevalence data are critical. Recently, the global trachoma program has made important investments in appropriately scoping out ${ }^{16}$ and mapping ${ }^{17-21}$ suspected endemic populations using standardized, quality-controlled, and qualityassured approaches. ${ }^{22-24}$ Where baseline TF prevalence is $<5 \%$, the A component is not indicated for trachoma elimination purposes, but the need for interventions to improve access to water and sanitation may be highlighted if current access is suboptimal. ${ }^{25}$ Where baseline TF prevalence is $\geq$ $5 \%, A, F$, and $E$ are indicated as noted earlier, with impact surveys due 6-12 months after the last planned round of MDA. ${ }^{26}$ Programs use impact survey TF prevalence to determine whether further MDA rounds should be planned. Impact survey TF prevalence $<5 \%$ signals an end to MDA for trachoma elimination purposes and the start of a 2-year surveillance period. At the end of those 2 years, a pre-validation surveillance survey is undertaken to ensure that TF prevalence has not recrudesced to $\geq 5 \%$. $^{26}$

Baseline, ${ }^{21}$ impact, $^{27}$ and pre-validation surveillance ${ }^{28}$ surveys are generally all performed using population-based, 
two-stage cluster sampling. ${ }^{29}$ Survey costs are not insignificant. ${ }^{30-32}$ Trachoma programs are currently undergoing considerable expansion in an effort to achieve the World Health Assembly-endorsed goal of global elimination of trachoma as a public health problem. ${ }^{33,34}$ During a session of the 2018 meeting of the Coalition for Operational Research on neglected tropical diseases (NTDs), discussion focused on the proportion of EUs undergoing trachoma impact surveys in a defined period returning a TF prevalence estimate above the elimination threshold, a proportion sometimes referred to as the failure rate. This rate was said to be higher than the analogous failure rate of lymphatic filariasis transmission assessment surveys, with the implication being that money for trachoma elimination was being inefficiently spent on surveys conducted too soon. It led us to wonder: Is a nonzero failure rate necessarily bad? Here, we demonstrate that the answer is no, by modeling the financial cost of undertaking MDA with and without conducting impact surveys. And, because in this context failure turns out to be helpful, we will henceforth use the more neutral term continuation rate to refer to the proportion of EUs undergoing impact surveys that derive a renewed mandate for MDA.

\section{MATERIALS AND METHODS}

To obtain an impact survey continuation rate of $0 \%$ (and thereby save money on monitoring and evaluation by not needing to repeat impact surveys after further rounds of MDA), all impact surveys would need be delayed until a TF prevalence $<5 \%$ was thought to be virtually guaranteed. We therefore compared the cost of using impact surveys to guide decision-making on ongoing annual MDA with the cost of simply continuing MDA for another year, considering only the financial costs to the trachoma program in a single year of its operation.

We hypothesized a set of trachoma-endemic EUs in which, at the beginning of the program year, the recommended number of annual rounds of MDA for trachoma elimination purposes had already been completed. Assuming appropriate antibiotics were available, the trachoma program manager could-in theory-choose between two strategies:

(a) undertake an impact survey in each EU, then decide whether to stop or continue MDA in the EU on the basis of the survey outcome; or

(b) undertake another round of MDA in each EU, postponing impact surveys until the next year or beyond.

The cost of strategy (a) would be less than that of strategy (b) when

$$
C_{\text {survey }}+\left(P_{\text {continuation }} \times u c_{\mathrm{MDA}} \times \bar{N}\right)<u c_{\mathrm{MDA}} \times \bar{N} \text {, }
$$

where $C_{\text {survey }}$ is the financial cost of an impact survey in one EU, excluding salaries of (but including fieldwork per diems for) survey team members; $P_{\text {continuation }}$ is the impact survey continuation rate; $u c_{\mathrm{MDA}}$ is the unit cost of MDA per person per year excluding the cost of antibiotics and excluding salaries and per diems of distribution team members; and $\bar{N}$ is the mean EU population.
Rearranging, this occurs when

$$
\begin{aligned}
& P_{\text {continuation }}<\left(\left[u c_{\mathrm{MDA}} \times \bar{N}\right]-C_{\text {survey }}\right) /\left(u c_{\mathrm{MDA}} \times \bar{N}\right) \\
& \text { or when } P_{\text {continuation }}<\left(1-C_{\text {survey }}\right) /\left(u c_{\mathrm{MDA}} \times \bar{N}\right),
\end{aligned}
$$

that is, when the probability of continuation is less than $1 \mathrm{mi}-$ nus the ratio of the impact survey cost to the cost of one round of MDA.

We know that $u c_{\text {MDA }}$ (not just the total cost of MDA) depends on $N .^{35}$ The elasticity of $U c_{\text {MDA }}$ with respect to population size is about -0.5 , meaning that for a $10 \%$ increase in $N, u c_{M D A}$ decrease by a mean of $5 \%$. We therefore used a published webbased application (https://healthy.shinyapps.io/benchmark ${ }^{35}$ ) to generate estimates of $u c_{\mathrm{MDA}}$ for our analyses. This application requires several parameters to be specified; we assumed an MDA coverage rate of $85 \%$ would be achieved in the fourth year of a subnational, annual campaign distributing only antibiotics for trachoma, in a country other than a small-island developing state, using unpaid volunteers to distribute in the community (rather than in schools). Per-capita gross domestic product (GDP) and population density were set at \$936 and 123 people per $\mathrm{km}^{2}$, respectively: real-world data from the United Republic of Tanzania in 2017. These choices were consistent with the scenario under consideration: WHO recommends that programs achieve at least $80 \%$ coverage when undertaking antibiotic $\mathrm{MDA}^{3}$; where baseline TF prevalence is $10-29.9 \%$, an impact survey to determine whether or not MDA should continue would normally be undertaken before the fourth round, the United Republic of Tanzania is trachoma endemic, ${ }^{36}$ and so on. The derived $u c_{\text {MDA }}$ estimates were $\$ 0.13$ (2015 USD; 95\% Cl: $0.08-0.17), \quad \$ 0.18 \quad(0.11-0.23), \quad \$ 0.20 \quad(0.12-0.26), \quad \$ 0.23$ (0.14-0.29), \$0.28 (0.17-0.35), and 0.39 (0.24-0.49) for EUs of $500,000,250,000,200,000,150,000,100,000$, and 50,000 people, respectively.

$C_{\text {survey }}$ can also depend on $N$. The standard error of a prevalence estimate decreases as the sampling fraction increases, allowing smaller sample sizes (for the same level of precision) with smaller underlying populations. In practice, sample sizes do not vary much across the WHOrecommended EU population range: a decrease in EU population size from 250,000 to 100,000 decreases the estimated sample size requirement for 1 - to 9 -year-olds by only 2.3-3.2\%, depending on the other parameters used in the calculation. ${ }^{29}$ What if EUs are constructed to be even smaller than 100,000 people? Although the number of children that should be examined to maintain acceptable precision decreases more steeply, the requirement for those children to be chosen from at least 20 clusters $^{29}$ means that $C_{\text {survey }}$ tends not to fall far. Program data suggest variation in impact survey costs is driven primarily by context-specific expenditure on per diems and transport, with minor economies of scale seen when larger numbers of surveys are undertaken in a single round. ${ }^{32}$ To parameterize $C_{\text {survey }}$ for the current analyses, we used published data compiled from 322 trachoma impact and surveillance surveys conducted in 11 countries; the median per-EU financial cost (in 2017 USD) was $\$ 8,298$ (interquartile range [IQR]: \$6,532-\$10,111). ${ }^{32}$ (Surveillance surveys use the same systems and methods and have the same sample size requirements as impact surveys, and the costs of these two survey types do not differ significantly from each other [Mann-Whitney $P=0.68 ; 95 \% \mathrm{Cl}$ for cost 
difference-\$620-\$788]. ${ }^{32}$ It is therefore appropriate to use the median cost for both survey types combined as the $C_{\text {survey }}$ value in the present analyses.)

Our choices of, for example, per-capita GDP and population density when deriving $u c_{\mathrm{MDA}}$ estimates from https:// healthy.shinyapps.io/benchmark/ were necessarily arbitrary and made simply to parameterize the model. We therefore performed a separate analysis using the median $u c_{M D A}$ determined from 150 observations in 29 studies identified as part of a published systematic review: $\$ 0.20$ (2015 USD). ${ }^{35} \mathrm{We}$ converted $u c_{\text {MDA }}$ estimates from 2015 USD to 2017 USD using an inflation factor of $\times 1.0342$.

We obtained empirical data on $P_{\text {continuation }}$ by compiling global impact survey continuation rates using all surveys completed using Tropical Data (www.tropicaldata.org) in the calendar years 2017 and 2018. We used these inputs, and the same median and IQR $C_{\text {survey }}$ as earlier, ${ }^{32}$ to determine the global per-EU cost of strategies (a) and (b) and the $P_{\text {continuation }}$ at which the costs would equalize, for the same six illustrative $\bar{N}$ s.

As a case example, we compared the cost of implementing each strategy within the trachoma elimination program of the United Republic of Tanzania for 2017 and 2018. For this analysis, we used survey and cost data collected retrospectively from the actual surveys implemented during that period.

\section{RESULTS}

From January 1, 2017 to December 31, 2018, Tropical Data supported trachoma programs to complete 538 impact surveys in 25 countries, representing $92 \%$ of all impact surveys completed for trachoma globally during that 2-year period.

A total of 170 (32\%) of those 538 impact surveys returned estimates of TF prevalence in 1- to 9-year-olds of $\geq 5 \%$, indicating MDA continuation. Continuation rates ranged by country from $0 \%$ to $100 \%$ of EUs. Fourteen of 25 countries had nonzero continuation rates.

For EUs containing a mean of 100,000 people, the median cost of continuing MDA without doing impact surveys would be USD 28,957 per EU per year, whereas the median cost of doing impact surveys and continuing MDA only where indicated by TF prevalence would be USD 17,564 (Table 1). Continuing MDA without impact surveys becomes advantageous (in financial cost terms) only when the continuation rate exceeds $71 \%$.

In the United Republic of Tanzania in the 2 years from January 1, 2017 to December 31, 2018, 20 impact surveys were required. The continuation rate was $6 / 20$ (30\%). The cost of not doing impact surveys and just undertaking MDA in each of those 20 EUs (strategy [b]) would have been $\$ 409,721$. The cost of the process actually performed-undertaking impact surveys and implementing MDA only where indicated (strategy [a])—was $\$ 307,790$, a saving of $\$ 101,931$ (25\%, Table 2). Based on the local cost of MDA in 2017-2018 (\$0.0981 per person, Table 2), this is equivalent to the cost of undertaking MDA for more than one million people.

\section{DISCUSSION}

A trachoma elimination program in which all impact surveys estimate TF to be $<5 \%$ has waited too long to do them and will in the meantime have incurred unnecessary intervention costs. Doing surveys to determine whether MDA is still needed is generally cheaper than just continuing MDA. The qualification generally is needed in that statement because the certainty of the conclusion would diminish when survey costs or survey continuation rates rise, when MDA costs fall, or for mean EU populations less than 50,000 . This observation underlines the merit of the $2010 \mathrm{WHO}$ recommendation that trachoma program EUs be framed as populations of 100,000-250,000 people, ${ }^{3}$ a recommendation that tried to balance considerations relating to disease control, ethics, existing administrative divisions, local politics, and program costs. The cost element in that balance was intuitive; the present analyses allow the intuition to be formally tested-and found to be correct. Although it may not be straightforward for health ministries to combine local administrative areas with small populations into a single EU for trachoma elimination purposes, where local administrative areas have very small populations, doing so probably increases the cost efficiency of the elimination program.

Understanding that impact surveys save money even when some EUs fail them is important. The corollary-that a nonzero continuation rate should be welcomed-is even more important because it can seem counterintuitive. Spending money on monitoring and evaluation can make program managers and partners uncomfortable. The proportion of funds that can be spent on monitoring and evaluation is capped in some

TABLE 1

Cost per trachoma-endemic EU in a single programmatic year for (a) undertaking an impact survey in each EU, and then making a decision on whether to stop or continue annual antibiotic MDA for trachoma elimination purposes in that EU on the basis of the outcome; and (b) simply continuing MDA without first conducting impact surveys, and the continuation rate at which financial costs for the two strategies equalize, for different mean EU populations $(\bar{N})$

\begin{tabular}{|c|c|c|c|}
\hline $\bar{N}$ & $\begin{array}{l}\text { Cost per EU of impact surveys then MDA where } \\
\text { indicated }{ }^{*}, 2017 \text { USD } \dagger\end{array}$ & $\begin{array}{l}\text { Cost per EU of continuing MDA without first conducting } \\
\text { impact surveys } \ddagger, 2017 \text { USD } \uparrow\end{array}$ & $\begin{array}{l}\text { Impact survey continuation rate at which financial costs } \\
\text { equalize, } \% \dagger\end{array}$ \\
\hline 50,000 & $14,751(10,503-18,219)$ & $20,166(12,410-25,337)$ & $58(47-60)$ \\
\hline 100,000 & $17,564(12,158-21,694)$ & $28,957(17,581-36,197)$ & $71(62-72)$ \\
\hline 150,000 & $19,715(13,482-24,507)$ & $35,679(21,718-44,987)$ & $76(69-77)$ \\
\hline 200,000 & $21,536(14,474-27,320)$ & $41,368(24,820-53,778)$ & 79 (73-81) \\
\hline 250,000 & $23,190(15,633-29,140)$ & $46,539(28,440-59,466)$ & $82(77-82)$ \\
\hline 500,000 & $29,809(19,770-38,241)$ & $67,223(41,368-87,907)$ & $87(84-88)$ \\
\hline
\end{tabular}

$\mathrm{EU}=$ evaluation unit; IQR = interquartile range; MDA = mass drug administration. Calculations were based on the global median (and IQR of) impact survey costs from Stelmach et al.. ${ }^{32}$ the 2017-2018 global Tropical Data impact survey continuation rate of $32 \%$, and the global median (and 95\% Cls of) per-person financial cost of MDA from Fitzpatrick et al., ${ }^{35}$ inflated from 2015 USD to 2017 USD using a factor of $\times 1.0342$.

*Referred to in the text as "strategy (a)."

†First figure in each cell uses the median survey and MDA costs; figures in parentheses reflect the IQR of survey costs and $95 \% \mathrm{Cl}$ of MDA costs.

$\ddagger$ Referred to in the text as "strategy (b)." 
TABLE 2

Retrospective estimate of costs to the United Republic of Tanzania's trachoma elimination program of either (a) undertaking an impact survey in each EU in which one was due in 2017 or 2018 and then deciding whether to stop or continue annual antibiotic MDA for trachoma elimination purposes in that EU on the basis of the outcome; or (b) simply continuing MDA without first conducting impact surveys

\begin{tabular}{|c|c|c|c|c|c|c|c|c|c|}
\hline \multirow[b]{2}{*}{ District } & \multirow[b]{2}{*}{ EU } & \multirow[b]{2}{*}{$\begin{array}{l}\text { Year of } \\
\text { impact } \\
\text { survey }\end{array}$} & \multirow[b]{2}{*}{$\begin{array}{l}\text { Cost of impact } \\
\text { survey (USD) }\end{array}$} & \multirow[b]{2}{*}{$\begin{array}{l}\text { Estimated } \\
\text { population at the } \\
\text { time of impact } \\
\text { survey }\end{array}$} & \multirow[b]{2}{*}{$\begin{array}{l}\text { Cost of one } \\
\text { round MDA } \\
\text { (USD), if } \\
\text { needed }\end{array}$} & \multicolumn{2}{|c|}{ Strategy (a) } & \multirow[b]{2}{*}{$\begin{array}{l}\text { Strategy (b) } \\
\begin{array}{c}\text { Cost of MDA } \\
\text { (no impact } \\
\text { survey) }\end{array}\end{array}$} & \multirow[b]{2}{*}{$\begin{array}{l}\text { Annual saving } \\
\text { achieved using } \\
\text { strategy (a) rather } \\
\text { than (b) }\end{array}$} \\
\hline & & & & & & $\begin{array}{l}\text { Trachomatous } \\
\text { inflammation-follicular } \\
\text { prevalence category at } \\
\text { impact survey } \\
\text { (MDA needed?) }\end{array}$ & $\begin{array}{l}\text { Total cost of } \\
\text { impact survey + } \\
\text { MDA in year of } \\
\text { impact survey }\end{array}$ & & \\
\hline Nkasi & Nkasi & 2018 & $8,719.32$ & 318,958 & $28,884.11$ & $<5 \%$ (no) & $8,719.32$ & $28,884.11$ & $20,164.79$ \\
\hline Kalambo & Kalambo & 2018 & $7,610.23$ & 235,589 & $21,351.88$ & $5-9.9 \%$ (yes) & $28,962.11$ & $21,351.88$ & $-7,610.23$ \\
\hline Ngara & Ngara & 2018 & $9,501.14$ & 386,638 & $16,728.38$ & $<5 \%$ (no) & $9,501.14$ & $16,728.38$ & $7,227.24$ \\
\hline Songwe & Songwe & 2018 & $6,546.59$ & 153,820 & $10,947.88$ & $5-9.9 \%$ (yes) & $17,494.47$ & $10,947.88$ & $-6,546.59$ \\
\hline Chunya & Chunya & 2018 & $8,673.86$ & 163,315 & $12,595.67$ & $<5 \%$ (no) & 8,673.86 & $12,595.67$ & $3,921.80$ \\
\hline Bahi & Bahi & 2018 & $6,382.95$ & 251,080 & $22,565.15$ & $<5 \%$ (no) & $6,382.95$ & $22,565.15$ & $16,182.20$ \\
\hline Chemba & Chemba & 2018 & $8,401.14$ & 267,014 & $32,301.05$ & $5-9.9 \%$ (yes) & $40,702.19$ & $32,301.05$ & $-8,401.14$ \\
\hline Liwale & Liwale & 2018 & $7,610.23$ & 96,427 & $18,195.65$ & $<5 \%$ (no) & $7,610.23$ & $18,195.65$ & $10,585.42$ \\
\hline Longido & Longido & 2018 & $10,616.59$ & 144,410 & $18,468.33$ & $5-9.9 \%$ (yes) & $29,084.92$ & $18,468.33$ & $-10,616.59$ \\
\hline Monduli & Monduli & 2018 & $10,616.59$ & 186,477 & $20,565.78$ & $<5 \%$ (no) & $10,616.59$ & $20,565.78$ & $9,949.20$ \\
\hline Ngorongoro & Ngorongoro & 2018 & $11,611.66$ & 204,487 & $24,463.96$ & $10-29.9 \%$ (yes) & $36,075.61$ & $24,463.96$ & $-11,611.66$ \\
\hline Kalambo & Kalambo & 2017 & $10,341.64$ & 235,589 & $26,436.67$ & 5-9.9\% (yes) & $36,778.31$ & $26,436.67$ & $-10,341.64$ \\
\hline Kilindi & Kilindi & 2017 & $8,788.41$ & 258,372 & $26,248.10$ & $<5 \%$ (no) & $8,788.41$ & $26,248.10$ & $17,459.69$ \\
\hline Itigi & Itigi & 2017 & $8,427.59$ & 127,680 & $14,067.43$ & $<5 \%$ (no) & $8,427.59$ & $14,067.43$ & $5,639.83$ \\
\hline Manyoni & Manyoni & 2017 & $8,597.45$ & 213,010 & $20,933.81$ & $<5 \%$ (no) & $8,597.45$ & $20,933.81$ & $12,336.36$ \\
\hline Kongwa* & Kongwa south & 2017 & $6,973.86$ & 197,409 & $23,779.53$ & $<5 \%$ (no) & $6,973.86$ & $23,779.53$ & $7,970.53$ \\
\hline Kongwa* & Kongwa north & 2017 & $8,835.14$ & 113,042 & & $<5 \%$ (no) & $8,835.14$ & & \\
\hline Chamwino* & Chamwino south & 2017 & $8,256.36$ & 155,647 & $39,564.67$ & $<5 \%$ (no) & $8,256.36$ & $39,564.67$ & $22,820.48$ \\
\hline Chamwino* & Chamwino north & 2017 & $8,487.73$ & 147,574 & & $<5 \%$ (no) & $8,487.73$ & & \\
\hline Meatu & Meatu & 2017 & $8,821.82$ & 321,781 & $31,622.54$ & $<5 \%$ (no) & $8,821.82$ & $31,622.54$ & $22,800.72$ \\
\hline Totals & & & $173,820.28$ & $4,179,319$ & $409,720.59$ & - & $307,709.06$ & $409,720.59$ & $101,930.53$ \\
\hline
\end{tabular}

Disticts dividedinto two EUs for in

${ }^{*}$ Districts divided into two EUs for impact survey purposes.

program grants, and the view is sometimes expressed that funds allocated to these activities would be more productively used for disease control. This ignores the fact that programs must periodically reconfirm the presence of the disease being controlled. We have shown in this article that, assuming EUs are larger than 50,000 , and the continuation rate and unit costs are not too dissimilar from those included in our models, surveys save money for the program even in the year that they are performed. The reason for the saving is that MDA is delivered only to people who actually need it.

We note that survey data quality is paramount. ${ }^{23}$ Misclassifying EUs by conducting surveys with inadequate sample sizes, inappropriate sampling strategies, unstandardized graders, or inappropriate analysis methods invalidates any consideration of the use of surveys to improve cost efficiency. We note also that specific local conditions may fall outside the range of our illustrative calculations. The formulas and code (provided here: https://github.com/mathi-eu/ tis-failure) will allow replication or contextual adjustment.

Our analyses are relatively simple. They have several inherent limitations: the first of which is that they include only the financial costs to the program. We ignored the economic costs of the time of survey field-workers, time of survey participants, time of antibiotic distribution staff, and time of antibiotic recipients. Second, the $u c_{\mathrm{MDA}}$ estimates that we used may be imperfect. They were derived from studies across multiple NTDs ${ }^{35}$ because this allowed us to adjust for the elasticity of $u c_{\mathrm{MDA}}$ with changing $\mathrm{EU}$ population size. Our $u c_{\text {MDA }}$ estimates also excluded per diems of MDA teams; by contrast, we included the cost of per diems of survey fieldwork teams in our $C_{\text {survey. }}$ Actual published $u c_{\text {MDA }}$ estimates for trachoma elimination programs range from \$0.25 (Mali; year
2000-2002) to $\$ 1.37$ (South Sudan; 2010). ${ }^{37-39}$ Undertaking a preparatory population census or return household visits to maximize population coverage makes $u c_{\mathrm{MDA}}$ more expensive. ${ }^{37}$ Third, for the sake of simplicity and robustness, we ignored the finite population correction factor that can be used to reduce survey sample sizes for EUs with smaller populations ${ }^{29}$; this would have reduced our $C_{\text {survey. }}$ Fourth, again for the sake of simplicity, we limited our analyses to costs in the program year in which impact surveys are due. This disregarded the cost of ongoing annual MDA in subsequent years when the likelihood of it being necessary for trachoma elimination purposes would continue to wane. Fifth and perhaps most critically, we ignored externalities that would need to be accounted for were annual antibiotic MDA to continue indefinitely without regular affirmation of need. These externalities include a perceived lack of progress toward public health goals, with resulting loss of stakeholder confidence ${ }^{40}$; economic and environmental costs of manufacture and shipment of antibiotics; and possible emergence of antimicrobial resistance. ${ }^{41,42}$ Each of these five limitations is inherently conservative: had we incorporated the relevant considerations in our model, the case for doing more impact surveys rather than fewer would have been even more compelling. This article, then, presents the short-term financial rationale for undertaking high-quality impact surveys at the time when they are due.

The potential externalities of completely interrupting transmission of ocular C. trachomatis, ${ }^{43-45}$ reducing transmission of genital C. trachomatis, ${ }^{46}$ improving child survival, ${ }^{47,48}$ or eradicating yaws ${ }^{49-51}$ might, of course, strengthen the argument for continuing MDA. (Evidence for each of these possible outcomes of MDA is incomplete.) 
Similarly, if early discontinuation of MDA was strongly associated with later recrudescence of active trachoma, then both the benefit of continuing MDA for longer and the eventual financial cost of not doing so would be likely to increase. We also disregard the externalities involved in undertaking integrated surveys ${ }^{52}$ and integrated disease control and elimination programs, ${ }^{53}$ which might significantly affect the economic equation.

An additional limitation of this study comes in considering how to apply its conclusions. Programs that have conducted impact surveys for only a few EUs will have continuation rates that are liable to change profoundly as more local experience accrues. And perhaps more importantly, use of a high continuation rate as the lone metric to justify omitting impact surveys would be to ignore the important nonfinancial considerations outlined earlier.

It is worth noting that the counterfactual scenario that we presented-of simply continuing MDA for trachoma until impact survey failure becomes extremely unlikely-would be difficult to put into practice, for two reasons. First, to make donated drug available, the International Trachoma Initiative (which serves as the steward for Pfizer's [New York, NY] Zithromax ${ }^{\circledR}$ donation) requires program managers to provide evidence of ongoing need for MDA in the form of high-quality TF prevalence data. ${ }^{8}$ Without the donation, continuation of MDA would require azithromycin to be purchased, increasing $u c_{\text {MDA }}$. Second, we do not yet know enough to be able to confidently predict the number of annual rounds of MDA required to reduce the TF prevalence in any particular EU to < $5 \%$. Many variables, including parameters related to water, sanitation, eye-seeking flies, facial cleanliness, and population density, ${ }^{2}$ are associated with TF prevalence and could conceivably modify the effect of antibiotic treatment; the $F$ and E components of SAFE attempt to influence some of these parameters in parallel with antibiotic treatment, ${ }^{54}$ but have unknown effectiveness. The influence of EU-level antibiotic coverage (let alone heterogeneity of coverage spatially or by age and gender) is unclear. ${ }^{55,56}$ Given increasing concern about global antimicrobial resistance and the need to preserve the utility of macrolides, ${ }^{57}$ taking steps to ensure that antibiotic MDA occurs only where and when justified is critical, particularly if it also allows scarce global health dollars to be directed to other areas of need.

Although our analysis was driven by trachoma program data, similar considerations apply to other disease elimination efforts in which mass interventions are undertaken. Other NTD programs provide an immediate parallel. ${ }^{58} \mathrm{As}$ a touchstone for the 2030 Agenda for Sustainable Development, the movement to control, eliminate, and eradicate NTDs has few equals, such is the impact of the diseases on the impoverished populations in which they thrive. ${ }^{59}$ Good data are critical for all. ${ }^{60}$ We hope that this article will encourage ongoing support for both interventions against these diseases and the high-quality monitoring and evaluation needed to guide implementation.

Received June 16, 2020. Accepted for publication July 12, 2020.

Published online October 5, 2020.

Note: The World Health Organization holds the copyright to this article and has granted the publisher permission for the reproduction of this article.
Disclaimer: The authors alone are responsible for the views expressed in this article, which do not necessarily represent the views, decisions, or policies of the institutions with which the authors are affiliated or the U.S. government.

Disclosure: This article was developed based in part on discussions at a session of the 2018 annual meeting of the Coalition for Operational Research on Neglected Tropical Diseases, in New Orleans, LA, chaired by M. A. B. and P. J. H. A. W. S., M. B., C. F., A. B. K., and M. N. M. are staff members of WHO. P. J. H., A. B., and K. R. are employed by the International Trachoma Initiative at the Task Force for Global Health, which receives an operating budget and research funds from Pfizer Inc., the manufacturers of Zithromax ${ }^{\circledR}$ (azithromycin). M. A. B., J. M. N., L. A. R., and R. S. were staff members of the ENVISION Project, implemented with funding from the US Agency for International Development (USAID) by RTI International under cooperative agreement number AID-OAA-A-11-00048. ENVISION supported national neglected tropical disease (NTD) control programs for the control and elimination of seven targeted NTDs, including trachoma. One of the national NTD programs supported was that of the United Republic of Tanzania, in which U. J. M., G. K., and A. N. were employed. A. W. M. is an employee of USAID. I. J. and T. M. are staff members of Sightsavers, which receives funding from multiple donors for the control and elimination of NTDs, including trachoma. EMHE receives salary support from the International Trachoma Initiative. Other than through individual contributions of the named authors, none of these funders had any role in project design; in project implementation or analysis; in interpretation of data; in the decisions on where, how, or when to publish in the peer-reviewed press; or in preparation of the manuscript.

Authors' addresses: Anthony W. Solomon, Mathieu Bangert, Christopher Fitzpatrick, and Mwelecele N. Malecela, Department of Control of Neglected Tropical Diseases, World Health Organization, Geneva, Switzerland, E-mails: solomona@who.int, bangertm@who.int, fitzpatrickc@ who.int, and malecelam@who.int. Pamela J. Hooper, Ana Bakhtiari, and Kristen Renneker, International Trachoma Initiative, Task Force for Global Health, Decatur, GA, E-mails: phooper@taskforce.org, abakhtiari@ taskforce.org, and krenneker@taskforce.org. Upendo J. Mwingira and George Kabona, Neglected Tropical Disease Control Program, Ministry of Health, Community Development, Gender, Elderly and Children, Dodoma, United Republic of Tanzania, E-mails: umwingira@yahoo.com and kabona.george@afya.go.tz. Molly A. Brady, Jeremiah M. Ngondi, Lisa A. Rotondo, and Rachel Stelmach, RTI International, Washington, DC, E-mails: mbrady@rti.org, ingondi@rti.org, Irotondo@rti.org, and rstelmach@rti.org. lain Jones and Tom Millar, Sightsavers, Haywards Heath, United Kingdom, E-mails: ijones@sightsavers.org and tmillar@ sightsavers.org. Amir B. Kello, Expanded Special Project for Elimination of Neglected Tropical Diseases, World Health Organization Regional Office for Africa, Brazzaville, Congo, E-mail: kelloa@who.int. Aryc W. Mosher, United States Agency for International Development, Washington, DC, E-mail: amosher@usaid.gov. Andreas Nshala, IMA World Health, Dar es Salaam, United Republic of Tanzania, and Department of International Maternal and Child Health, Faculty of Medicine and Pharmacy, University of Uppsala, Uppsala, Sweden, E-mail: andreas.nshala@gmail.com. Emma M. Harding-Esch, Clinical Research Department, London School of Hygiene \& Tropical Medicine, London, United Kingdom, E-mail: emma.harding-esch@ishtm.ac.uk.

This is an open-access article distributed under the terms of the Creative Commons Attribution (CC-BY) License, which permits unrestricted use, distribution, and reproduction in any medium, provided the original author and source are credited.

\section{REFERENCES}

1. Habtamu E et al., 2015. Trachoma and relative poverty: a casecontrol study. PLoS Negl Trop Dis 9: e0004228.

2. Taylor HR, Burton MJ, Haddad D, West S, Wright H, 2014. Trachoma. Lancet 384: 2142-2152.

3. World Health Organization, 2010. Report of the 3rd Global Scientific Meeting on Trachoma. Johns Hopkins University, Baltimore, MA, July 19-20, 2010, WHO/PBD/2.10. Geneva, Switzerland: WHO. 
4. Thabit AA et al., 2018. Prevalence of trachoma in Yemen: results of population-based prevalence surveys of 42 evaluation units in nine governorates. Ophthalmic Epidemiol 25: 62-69.

5. Amer K et al., 2018. Prevalence of trachoma in four marakez of Elmenia and Bani Suef Governorates, Egypt. Ophthalmic Epidemiol 25: 70-78.

6. Evans JR, Solomon AW, Kumar R, Perez A, Singh BP, Srivastava RM, Harding-Esch E, 2019. Antibiotics for trachoma. Cochrane Database Syst Rev 9: CD001860.

7. Thylefors B, Dawson CR, Jones BR, West SK, Taylor HR, 1987. A simple system for the assessment of trachoma and its complications. Bull World Health Organ 65: 477-483.

8. International Trachoma Initiative, 2019. Zithromax Management Guide 2019: How to Successfully Apply for, Administer and Manage the Zithromax Donation for Trachoma Elimination. Decatur, GA: International Trachoma Initiative.

9. Bailey RL, Arullendran P, Whittle HC, Mabey DC, 1993. Randomised controlled trial of single-dose azithromycin in treatment of trachoma. Lancet 342: 453-456.

10. Atik B, Thanh TT, Luong VQ, Lagree S, Dean D, 2006. Impact of annual targeted treatment on infectious trachoma and susceptibility to reinfection. JAMA 296: 1488-1497.

11. Blake IM, Burton MJ, Solomon AW, West SK, Basanez MG, Gambhir M, Bailey RL, Mabey DC, Grassly NC, 2010. Targeting antibiotics to households for trachoma control. PLOS Neg/ Trop Dis 4: e862.

12. Solomon AW, Akudibillah J, Abugri P, Hagan M, Foster A, Bailey RL, Mabey DCW, 2001. Pilot study of the use of community volunteers to distribute azithromycin for trachoma control in Ghana. Bull World Health Organ 79: 8-14.

13. Solomon AW, Zondervan M, Kuper H, Buchan JC, Mabey DCW, Foster A, 2006. Trachoma Control: A Guide for Programme Managers. Geneva, Switzerland: World Health Organization.

14. Ejere HO, Alhassan MB, Rabiu M, 2015. Face washing promotion for preventing active trachoma. Cochrane Database Syst Rev 2: CD003659.

15. Rabiu M, Alhassan MB, Ejere HO, Evans JR, 2012. Environmental sanitary interventions for preventing active trachoma. Cochrane Database Syst Rev 2012: CD004003.

16. Correia $\mathrm{M}$ et al., 2018. A search for trachoma in Timor-Leste: no evidence to justify undertaking population-based prevalence surveys. Ophthalmic Epidemiol 25: 131-137.

17. Abdala $\mathrm{M}$ et al., 2017. The epidemiology of trachoma in Mozambique: results of 96 population-based prevalence surveys. Ophthalmic Epidemiol 25: 201-210.

18. Bero B et al.; Global Trachoma Mapping Project, 2016. Prevalence of and risk factors for trachoma in Oromia regional state of Ethiopia: results of 79 population-based prevalence surveys conducted with the global trachoma mapping project. Ophthalmic Epidemiol 23: 392-405.

19. Kilangalanga $\mathrm{J}$ et al.; Global Trachoma Mapping Project, 2018. Trachoma in the Democratic Republic of the Congo: results of 46 baseline prevalence surveys conducted with the global trachoma mapping project. Ophthalmic Epidemiol 25: 192-200.

20. Mpyet $C$ et al.; Global Trachoma Mapping Project, 2017. Prevalence of trachoma in Kano state, Nigeria: results of 44 local government area-level surveys. Ophthalmic Epidemiol 24: 195-203.

21. Kalua K, Chisambi A, Chinyanya D, Kamwendo Z, Masika M, Willis R, Flueckiger RM, Pavluck AL, Solomon AW; Global Trachoma Mapping Project, 2016. Completion of baseline trachoma mapping in Malawi: results of eight population-based prevalence surveys conducted with the global trachoma mapping project. Ophthalmic Epidemiol 23: 32-38.

22. Solomon AW et al., 2015. The global trachoma mapping project: methodology of a 34-country population-based study. Ophthalmic Epidemiol 22: 214-225.

23. Solomon AW et al.; Global Trachoma Mapping Project, 2018. Quality assurance and quality control in the global trachoma mapping project. Am J Trop Med Hyg 99: 858-863.

24. Solomon AW, Le Mesurier RT, Williams WJ, 2018. A diagnostic instrument to help field graders evaluate active trachoma. Ophthalmic Epidemiol 25: 399-402.
25. Boisson S, Engels D, Gordon BA, Medlicott KO, Neira MP, Montresor A, Solomon AW, Velleman Y, 2016. Water, sanitation and hygiene for accelerating and sustaining progress on neglected tropical diseases: a new global strategy 2015-20. Int Health 8 (Suppl 1): i19-i21.

26. World Health Organization, Strategic and Technical Advisory Group on Neglected Tropical Diseases, 2015. Technical Consultation on Trachoma Surveillance. Task Force for Global Health, September 11-12, 2014, Decatur, GA, WHO/HTM/ NTD/2015.02. Geneva, Switzerland: WHO.

27. Mpyet $C$ et al., 2018. Impact survey results after SAFE strategy implementation in fifteen local government areas of Kebbi, Sokoto and Zamfara states, Nigeria. Ophthalmic Epidemiol 25: 103-114.

28. Debrah O et al., 2017. Elimination of trachoma as a public health problem in Ghana: providing evidence through a pre-validation survey. PLoS Negl Trop Dis 11: e0006099.

29. World Health Organization, Strategic and Technical Advisory Group on Neglected Tropical Diseases, 2018. Design Parameters for Population-Based Trachoma Prevalence Surveys. WHO/HTM/NTD/PCT/2018.07. Geneva, Switzerland: WHO.

30. Chen C, Cromwell EA, King JD, Mosher A, Harding-Esch EM, Ngondi JM, Emerson PM, 2011. Incremental cost of conducting population-based prevalence surveys for a neglected tropical disease: the example of trachoma in 8 national programs. PLoS Negl Trop Dis 5: e979.

31. Trotignon G et al., 2017. The cost of mapping trachoma: data from the global trachoma mapping project. PLoS Negl Trop Dis 11: e0006023.

32. Stelmach RD, Flueckiger RM, Shutt J, Davide-Smith M, Solomon AW, Rotondo L, Mosher AW, Baker M, Willis R, Ngondi J, 2019. The costs of monitoring trachoma elimination: evaluating the costs of trachoma impact, surveillance, and trachomatous trichiasis (TT)-only surveys. PLoS Negl Trop Dis 13: e0007605.

33. Solomon AW, Emerson PM, Resnikoff S, 2017. Trachoma then and now: update on mapping and control. Community Eye Health 30: 90-91.

34. World Health Assembly, 1998. Global Elimination of Blinding Trachoma. 51st World Health Assembly, May 16, 1998, Geneva, Switzerland, Resolution WHA51.11. Geneva, Switzerland: WHO.

35. Fitzpatrick C, Fleming FM, Madin-Warburton M, Schneider T, Meheus F, Asiedu K, Solomon AW, Montresor A, Biswas G, 2016. Benchmarking the cost per person of mass treatment for selected neglected tropical diseases: an approach based on literature review and meta-regression with web-based software application. PLoS Negl Trop Dis 10: e0005037.

36. Mwingira UJ et al., 2016. Progress of trachoma mapping in Mainland Tanzania: results of baseline surveys from 2012 to 2014. Ophthalmic Epidemiol 23: 373-380.

37. Harding-Esch E et al., 2015. Costs of testing for ocular Chlamydia trachomatis infection compared to mass drug administration for trachoma in the Gambia: application of results from the PRET study. PLoS Negl Trop Dis 9: e0003670.

38. Kolaczinski JH, Robinson E, Finn TP, 2011. The cost of antibiotic mass drug administration for trachoma control in a remote area of South Sudan. PLoS Negl Trop Dis 5: e1362.

39. Schemann JF, Guinot C, Traore L, Zefack G, Dembele M, Diallo I, Traore A, Vinard P, Malvy D, 2007. Longitudinal evaluation of three azithromycin distribution strategies for treatment of trachoma in a sub-Saharan African country, Mali. Acta Trop 101: 40-53.

40. Courtright $P$ et al., 2018. Strengthening the links between mapping, planning and global engagement for disease elimination: lessons learnt from trachoma. Br J Ophthalmol 102: 1324-1327.

41. O'Brien KS, Emerson P, Hooper PJ, Reingold AL, Dennis EG, Keenan JD, Lietman TM, Oldenburg CE, 2018. Antimicrobial resistance following mass azithromycin distribution for trachoma: a systematic review. Lancet Infect Dis 19: e14-e25.

42. Doan T et al.; MORDOR Study Group, 2019. Macrolide resistance in MORDOR I - a cluster-randomized trial in Niger. NEngl J Med 380: 2271-2273. 
43. Chidambaram JD et al., 2006. Effect of a single mass antibiotic distribution on the prevalence of infectious trachoma. JAMA 295: 1142-1146.

44. House $\mathrm{Jl}$ et al., 2009. Assessment of herd protection against trachoma due to repeated mass antibiotic distributions: a cluster-randomised trial. Lancet 373: 1111-1118.

45. Solomon AW et al., 2008. Two doses of azithromycin to eliminate trachoma in a Tanzanian community. N Engl J Med 358: 1870-1871.

46. Marks M, Bottomley C, Tome H, Pitakaka R, Butcher R, Sokana O, Kako H, Solomon AW, Mabey DC, 2016. Mass drug administration of azithromycin for trachoma reduces the prevalence of genital Chlamydia trachomatis infection in the Solomon Islands. Sex Transm Infect 92: 261-265.

47. Keenan JD et al., 2018. Azithromycin to reduce childhood mortality in sub-Saharan Africa. N Engl J Med 378: 1583-1592.

48. Porco TC et al., 2009. Effect of mass distribution of azithromycin for trachoma control on overall mortality in Ethiopian children: a randomized trial. JAMA 302: 962-968.

49. Mitja O et al., 2015. Mass treatment with single-dose azithromycin for yaws. N Engl J Med 372: 703-710.

50. Marks M, Mitja O, Fitzpatrick C, Asiedu K, Solomon AW, Mabey DC, Funk S, 2017. Mathematical modeling of programmatic requirements for yaws eradication. Emerg Infect Dis 23: 22-28.

51. Ghinai R et al., 2015. A cross-sectional study of 'yaws' in districts of Ghana which have previously undertaken azithromycin mass drug administration for trachoma control. PLoS Neg/ Trop Dis 9: e0003496.

52. Taleo F et al.; Global Trachoma Mapping Project, 2017. Integrated mapping of yaws and trachoma in the five northern-most provinces of Vanuatu. PLoS Negl Trop Dis 11: e0005267.
53. Mwingira UJ, Means AR, Chikawe M, Kilembe B, Lyimo D, Crowley K, Rusibamayila N, Nshala A, Mphuru A, 2016. Integrating neglected tropical disease and immunization programs: the experiences of the Tanzanian Ministry of Health. Am J Trop Med Hyg 95: 505-507.

54. Pinsent A, Burton MJ, Gambhir M, 2016. Enhanced antibiotic distribution strategies and the potential impact of facial cleanliness and environmental improvements for the sustained control of trachoma: a modelling study. BMC Med 14: 71.

55. Amza A et al., 2017. Effectiveness of expanding annual mass azithromycin distribution treatment coverage for trachoma in Niger: a cluster randomised trial. $\mathrm{Br} J$ Ophthalmol 102: 680-686.

56. Oldenburg CE et al., 2018. Comparison of mass azithromycin coverage targets of children in Niger: a cluster-randomized trachoma trial. Am J Trop Med Hyg 98: 389-395.

57. Levine MM, Simon R, 2018. The gathering storm: is untreatable typhoid fever on the way? mBio 9: e00482-18.

58. Brady MA, Stelmach R, Davide-Smith M, Johnson J, Pou B, Koroma J, Frimpong K, Weaver A, 2017. Costs of transmission assessment surveys to provide evidence for the elimination of lymphatic filariasis. PLoS Negl Trop Dis 11: e0005097.

59. Bangert M, Molyneux DH, Lindsay SW, Fitzpatrick C, Engels D, 2017. The cross-cutting contribution of the end of neglected tropical diseases to the sustainable development goals. Infect Dis Poverty 6: 73.

60. Malecela MN, 2019. Reflections on the decade of the neglected tropical diseases. Int Health 11: 338-340. 